\title{
Inhibitory Effect of Propolis on Platelet Aggregation In Vitro
}

\author{
Yun-Xiang Zhang, ${ }^{1}$ Ting-Ting Yang, ${ }^{2}$ Liu Xia, ${ }^{3}$ Wei-Fen Zhang, ${ }^{2}$ Jia-Fu Wang, ${ }^{4}$ and \\ Ya-Ping $\mathrm{Wu}^{5}$ \\ ${ }^{1}$ Department of Pathology, Weifang People's Hospital, Weifang, Shandong Province 261041, China \\ ${ }^{2}$ School of Pharmacy, Weifang Medical University, Weifang, Shandong Province 261053, China \\ ${ }^{3}$ Department of Ophthalmology, Weifang Medical University, Weifang, Shandong Province 261053, China \\ ${ }^{4}$ Department of Pathology and Pathophysiology, Taishan Medical University, Taian, Shandong Province 271016, China \\ ${ }^{5}$ Departments of Haematology of University Medical Center, Utrecht University, 3508GA Utrecht, Netherlands
}

Correspondence should be addressed to Yun-Xiang Zhang; zhangbing199592@163.com

Received 23 February 2017; Accepted 2 May 2017; Published 10 October 2017

Academic Editor: Wenxin Niu

Copyright (c) 2017 Yun-Xiang Zhang et al. This is an open access article distributed under the Creative Commons Attribution License, which permits unrestricted use, distribution, and reproduction in any medium, provided the original work is properly cited.

\begin{abstract}
Platelet hyperactivity plays an important role in arterial thrombosis and atherosclerosis. The present study was aimed to investigate the effects of different extracts of propolis and components of flavonoids on platelet aggregation. Platelet-rich plasma was prepared and incubated in vitro with different concentrations of the tested extracts and components of flavonoids. Platelets aggregation was induced by different agonists including adenosine diphosphate (ADP, $10 \mu \mathrm{M}$ ), thrombin receptor activator peptide (TRAP, $50 \mu \mathrm{M})$, and collagen $(5 \mu \mathrm{g} / \mathrm{mL})$. At $25 \mathrm{mg} / \mathrm{L}$ to $300 \mathrm{mg} / \mathrm{mL}$, the water extract propolis (WEP) inhibited three agonists-induced platelet aggregations in a dose-dependent manner. The flavonoids isolated from the propolis also showed markedly inhibited platelet aggregation induced by collagen, ADP, and TRAP, respectively. The components including caffeic acid phenethyl ester (CAPE), galangin, apigenin, quercetin, kaempferol, ferulic acid, rutin, chrysin, pinostrobin, and pinocembrin and their abilities of inhibiting platelet aggregation were studied. It was concluded that propolis had an antiplatelet action in which flavonoids were mainly implicated.
\end{abstract}

\section{Introduction}

Nowadays, cardiovascular diseases (CVD) are the leading cause of morbidity and mortality worldwide [1-3] and bring a huge burden to the world economic development and people's living standard. It has been widely known that platelets play important roles in both hemostasis and pathogenesis of CVD such as acute coronary syndrome [4]. Platelet inhibition has shown improved short- and long-term clinical outcomes for CVD patients. However, increased bleeding risk and the high rates of recurrent ischemic events could not be ignored [5]. Furthermore, the activation of platelets was also related to circulation and vascular damage in patients with hypertension and diabetes [6]. Antiplatelet drugs used clinically to treat and prevent coronary syndromes and stroke are accompanied by a variety of side effects such as thrombocytopenia, hemorrhage, gastric ulcers, and therapeutic resistance [7, 8]. More safe and effective antiplatelet drugs would be urgently needed based on the current situation.

In recent, natural products and alternative medicine are now getting significant attention. Propolis, a complex mixture containing various compounds, such as flavonoids, terpenes, $\beta$-steroids, aromatic aldehydes, and alcohols, is a plant-derived substance collected from plant materials by honeybees $[9,10]$. Propolis is extensively used in food and beverages to improve health because of its unique pharmacological activities including antimicrobial, antioxidant, immunomodulatory, hepatoprotective, antitumor, and cardioprotective effects [11-21]. Recently, Liu and his colleagues put forward that chrysin in propolis performs antiplatelet activity via inhibiting platelet alphaIIbbeta3-mediated signaling pathway [22]. In addition, evidence data showed that propolis coated Co-Cr could significantly reduce adhesion 
of platelets [23]. Many studies demonstrated that the propolis components were varied in different geographic and climatic zones [24]. Thus, the aim of the present study was to examine the effects of propolis extracts on human platelet aggregation in vitro and to identify the nature of the compounds responsible for the antiplatelet activity.

\section{Materials and Methods}

2.1. Materials. Propolis sample was obtained from Taishan fir in the autumn. Adenosine diphosphate (ADP) was purchased from Arkray (Aggrepack, Japan). Collagen was purchased from NYCOMED (Kollagenreagens Horm, Austria). Thrombin receptor activator peptide (TRAP) was purchased from Bachem (Germany). Caffeic acid phenethyl ester (CAPE), galangin, acacetin, and pinostrobin were purchased from Sigma Chemical Co. (USA).

2.2. Preparation of Water Extract of Propolis (WEP) and Flavonoid. According to previous research [25], a certain amount of dried propolis sample frozen at $-20^{\circ} \mathrm{C}$ was dissolved in $30 \mathrm{~mL}$ of distilled water at $60^{\circ} \mathrm{C}$ for $7 \mathrm{~h}$. The crude extract was filtered, then centrifuged at $28000 \mathrm{rpm}$ for $30 \mathrm{~min}$, and the supernatants were concentrated under reduced pressure to produce the WEP. Flavonoid was obtained from another $10.0 \mathrm{~g}$ dried propolis dissolved in $300 \mathrm{~mL} 70 \%$ ethanol $7 \mathrm{~h}$ at room temperature using the same method [26].

2.3. Component Analysis of WEP and Flavonoid. For the components of WEP and flavonoid, a ZQ-4000 HPLC apparatus (Waters, USA) was used. The chromatographic separation was achieved using a Waters Symmetry C18 column $(4.6 \mathrm{~mm}$ I.D. $\times 150 \mathrm{~mm}, 3.5 \mu \mathrm{m})$, with the column oven temperature maintained at $25^{\circ} \mathrm{C}$. The mobile phase consisted of acetonitrile and $2 \%$ acetic acid. The mobile phase flow rate was $0.2 \mathrm{~mL} / \mathrm{min}$, and $\mathrm{UV}$ absorbance was monitored at $280 \mathrm{~nm}$. Diluted standard solutions of galangin, CAPE, apigenin, quercetin, kaempferol, ferulic acid, rutin, chrysin, pinostrobin, and pinocembrin were analyzed in the same HPLC conditions, and furthermore, the calibration of the detector response was done. Quantification of the main bioactive compounds from WEP and flavonoid was based on the calibration curves. The results were confirmed by the Department of Agriculture Bee Products Quality Supervision and Inspection Center (Beijing).

2.4. The Platelet Aggregation Tests. Human platelet suspensions were prepared as previously described [27]. In this study, human volunteers had been given informed consent. In brief, blood was collected from healthy human volunteers who had taken no medicine during the preceding 2 weeks and was mixed with $3.4 \% \mathrm{Na}$-citrate $(9: 1, \mathrm{vol} / \mathrm{vol})$. The blood was centrifugated at $1100 \mathrm{rpm}$ for $15 \mathrm{~min}$ at $20^{\circ} \mathrm{C}$. Then, platelet-rich plasma (PRP) was collected with pipette and stored at room temperature. The tubes containing PRP were centrifuged at $3000 \mathrm{rpm}$ for $10 \mathrm{~min}$ at $20^{\circ} \mathrm{C}$ to obtain the platelet-pool plasma (PPP). After a platelet count (Sysmex SE-9000, Kobe, Japan), a standard concentration of $200 \times 109 / \mathrm{L}$ was obtained by diluting PRP with PPP.
TABLE 1: The components of WEP and flavonoids.

\begin{tabular}{lcc}
\hline Compounds of propolis & $\begin{array}{c}\text { Concentration in } \\
\text { WEP }(\mathrm{mg} / \mathrm{L})\end{array}$ & $\begin{array}{c}\text { Concentration in } \\
\text { flavonoids }(\mathrm{mg} / \mathrm{g})\end{array}$ \\
\hline Galangin & 4477.09 & 37.24 \\
CAPE & 6329.74 & 5.55 \\
Apigenin & 305.76 & 0.34 \\
Quercetin & 2681.01 & 0.17 \\
Kaempferol & 897.80 & 1.79 \\
Ferulic acid & 3593.05 & 0.06 \\
Rutin & - & 3.56 \\
Chrysin & - & 13.94 \\
Pinostrobin & - & 95.52 \\
Pinocembrin & - & 0.84 \\
\hline
\end{tabular}

The turbidimetric method was applied to measure platelet aggregation stimulated by the various kinds of agonists using an aggregometer [28]. Previous study mentioned different flavonoid components present in propolis (CAPE, galangin, acacetin, and pinostrobin) were able to inhibit platelet aggregation, so CAPE, galangin, acacetin, and pinostrobin were tested in our study [29]. All aggregation tests were performed within $2 \mathrm{~h}$ after isolation and carried out in triplicate. Each person had his/her own 0\% PRP and 100\% PPP aggregation calibration. Before aggregation was started, standard platelet concentration was incubated in solutions of different concentrations, including WEP $(300 \mathrm{mg} / \mathrm{L}, 100 \mathrm{mg} / \mathrm{L}, 25 \mathrm{mg} / \mathrm{L})$, flavonoids $(400 \mathrm{mg} / \mathrm{L}, 100 \mathrm{mg} / \mathrm{L}, 25 \mathrm{mg} / \mathrm{L})$, CAPE $(352 \mu \mathrm{M}$, $88 \mu \mathrm{M}, 6 \mu \mathrm{M})$, galangin $(370 \mu \mathrm{M}, 185 \mu \mathrm{M}, 46 \mu \mathrm{M})$, acacetin $(352 \mu \mathrm{M}, 176 \mu \mathrm{M}, 44 \mu \mathrm{M})$, and pinostrobin $(370 \mu \mathrm{M}, 92 \mu \mathrm{M}$, $23 \mu \mathrm{M}$ ) for $30 \mathrm{~min}$ at the room temperature, then prewarmed at $37^{\circ} \mathrm{C}$ for two minutes. The aggregation was induced by ADP, collagen, or TRAP, respectively. The extent of aggregation was expressed in light transmission units.

2.5. Statistical Analysis. The results were shown as mean \pm standard deviations, and each experiment was performed in triplicate. Statistical analysis was carried out using SPSS19.0, and differences were considered to be significant at a level of $P<0.05$.

\section{Results and Discussion}

3.1. Chemical Components of Propolis. Flavonoids are the major constituents of propolis and contribute greatly to the pharmacological activities of propolis. Usually, the quality of propolis was based on flavonoids quality [30]. The contents of flavonoids depend on the harvest region because the characteristics of propolis are influenced by the local plant varieties and weather [31]. Report of component analysis of WEP and flavonoids was shown in Table 1. The contents of CAPE were the highest in the WEP, followed by galangin, ferulic acid, quercetin, kaempferol, and apigenin. Pinostrobin was the most abundant chemical compound in flavonoids, followed by galangin, chrysin, CAPE, rutin, kaempferol, pinocembrin, apigenin, quercetin, and ferulic acid. 


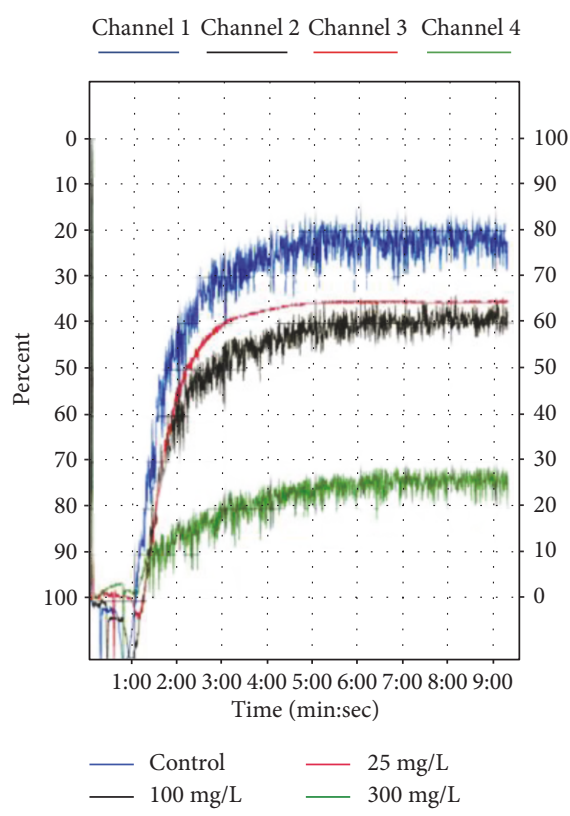

(a)

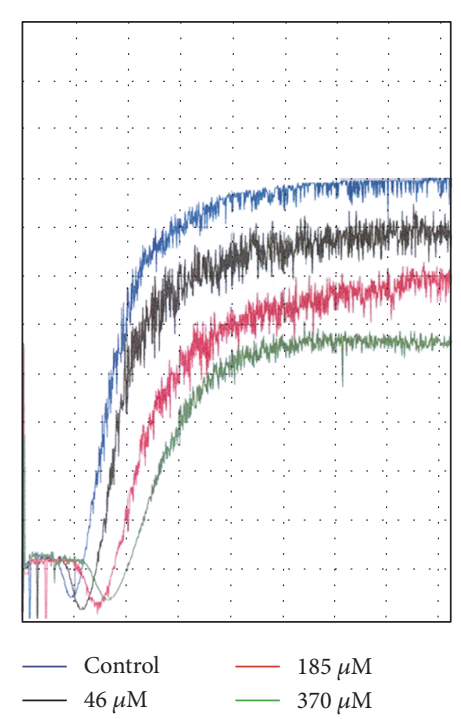

(d)

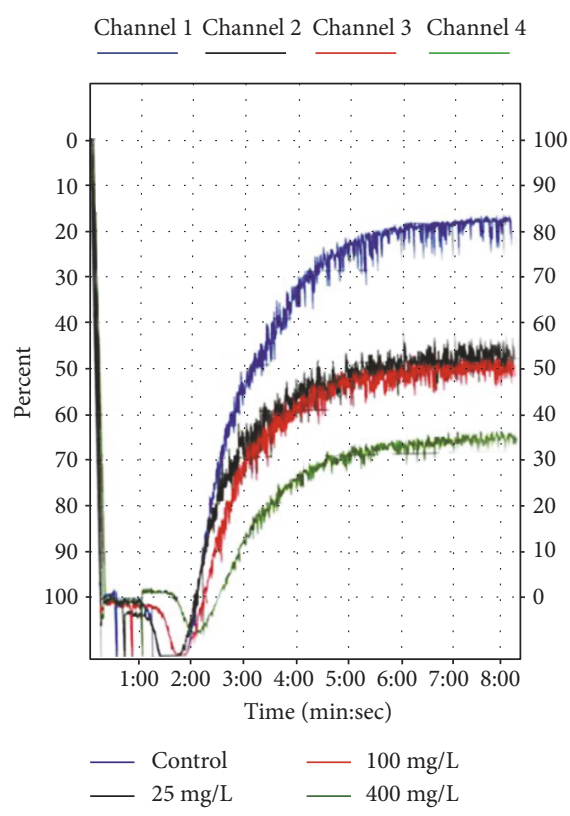

(b)

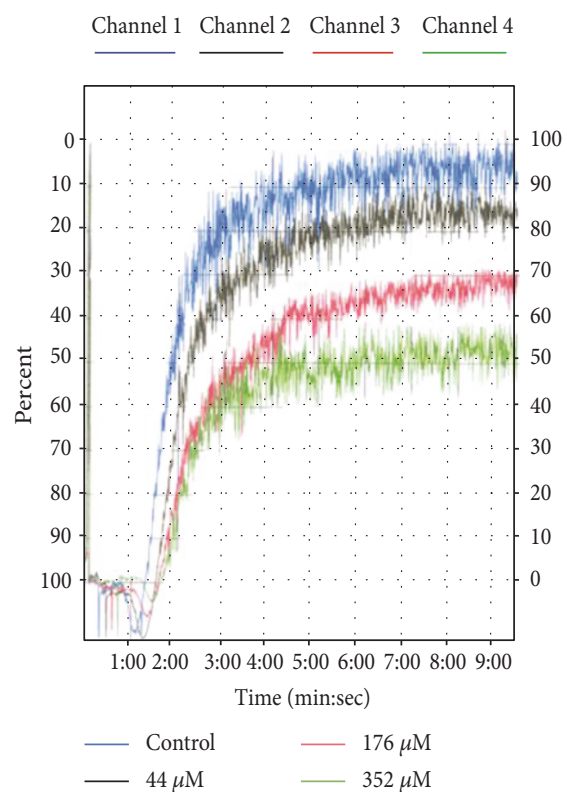

(e)

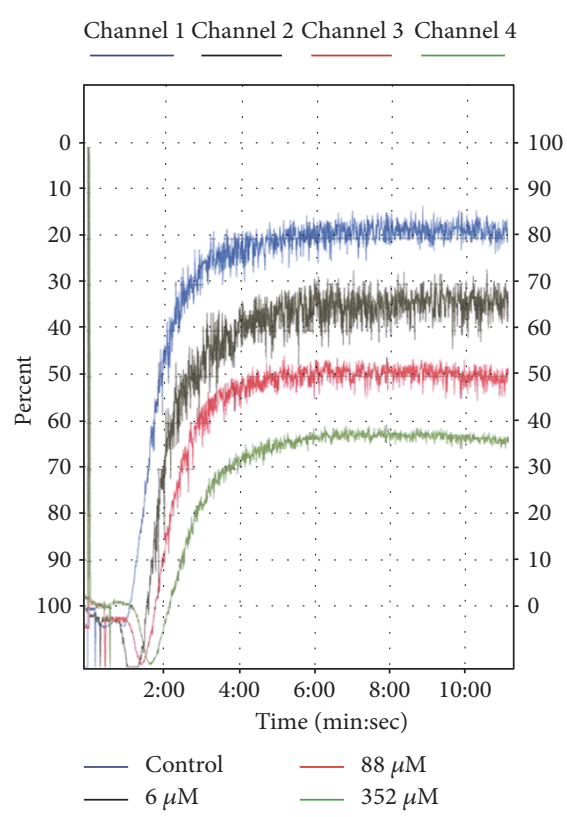

(c)

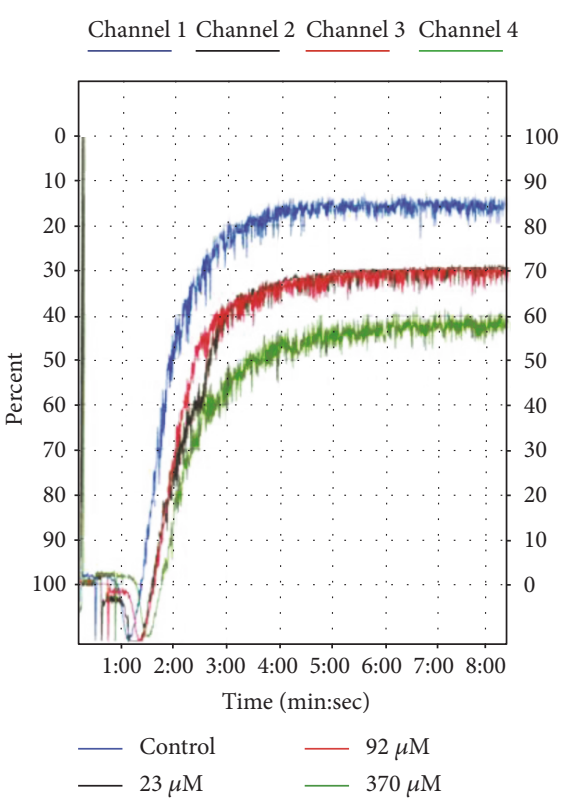

(f)

FIGURE 1: Original tracings showing the dose-dependent inhibitory effect of different extracts including WEP (a) and flavonoids (b) and pure components including CAPE (c), galangin (d), acacetin (e), and pinostrobin (f) on collagen-induced platelet aggregations in vitro.

3.2. The Inhibition Effect of Different Components on Platelet Aggregation Induced by Different Agonists. Results of the platelet aggregation tests were shown in Figures 1 and 2. The results showed that the crude WEP inhibited platelet aggregation in a dose-dependent manner, which might be stimulated with different agonists including ADP, collagen, and TRAP. For instance, $300 \mathrm{mg} / \mathrm{L}$ WEP significantly decreased platelet aggregation induced by ADP, collagen, and TRAP to $35.00 \pm 5.34 \%, 35.00 \pm 6.61 \%$, and $42.33 \pm$ $13.24 \%$ ( $n=3 ; P<0.01)$, respectively, indicating that propolis contains compounds having antiplatelet aggregation activity. This effect might be attributed to polar compounds such as flavonoids and polyphenols.

Flavonoids inhibited the three agonist-induced platelet aggregations in a dose-dependent manner, and the percent of inhibition were $53.11 \pm 1.90 \%, 51.12 \pm 9.30 \%$, and $51.98 \pm$ $22.20 \%$ at concentrations of $400 \mathrm{mg} / \mathrm{L}$, respectively. This finding was consistent with previous studies showing the antiplatelet aggregation activity of flavonoids in vitro [32] and in vivo [33]. We also test four purified components, including CAPE, galangin, acacetin, and pinocembrin. All test dose CAPE added to the PRP platelet aggregation 


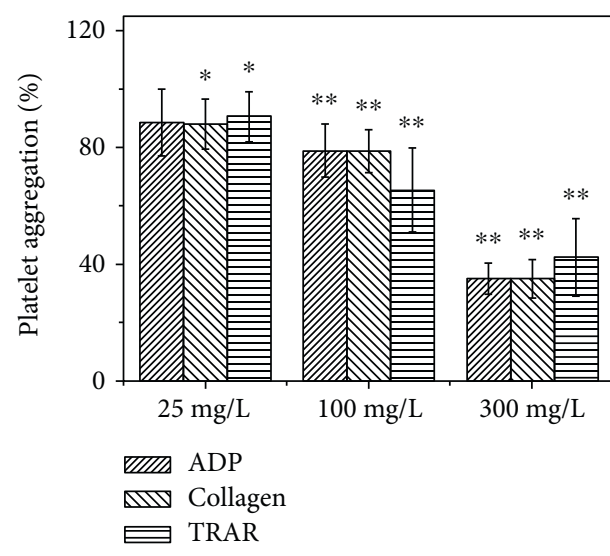

(a)

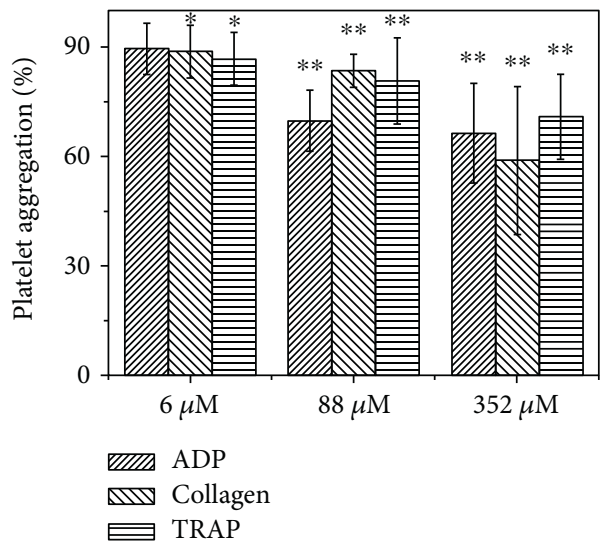

(c)

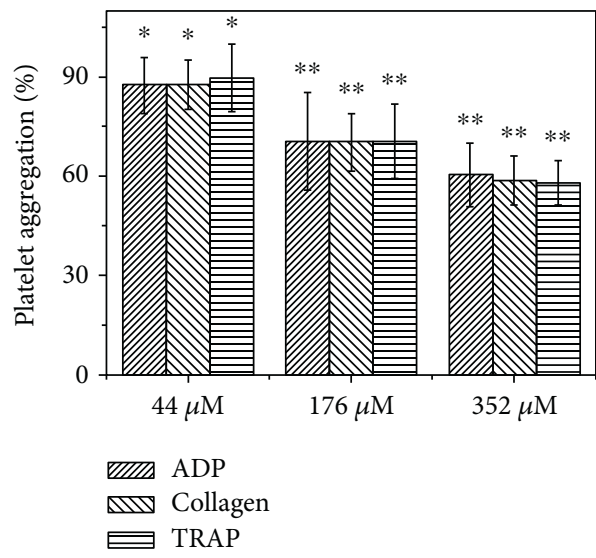

(e)

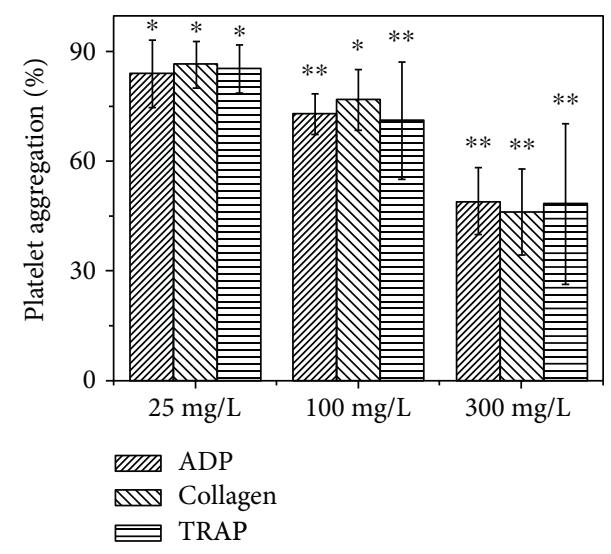

(b)

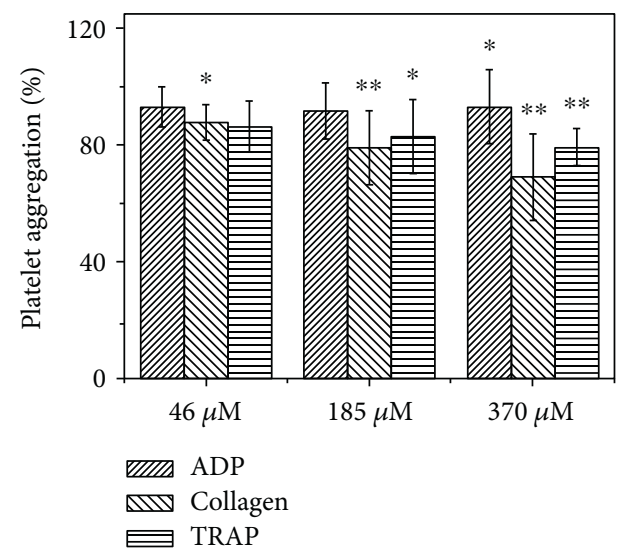

(d)

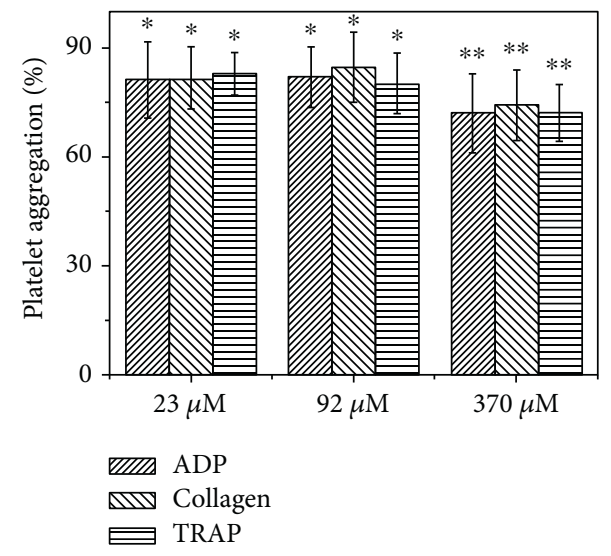

(f)

FIGURE 2: Inhibitory effect of different extracts including WEP (a) and flavonoids (b) and pure components including CAPE (c), galangin (d), acacetin (e), and pinostrobin (f) on platelet aggregation induced by different agonists including ADP, collagen, and TRAP, respectively. ${ }^{*}$ Compared with the control $(P<0.05)$ was observed. ${ }^{* *}$ Compared with the control $(P<0.01)$ was observed. Data are represented as the mean $\pm \mathrm{SD}(n=3)$.

induced by collagen and TRAP significantly decreased $(P<0.05)$, and the most antiplatelet aggregation effect occurred in the collagen-included platelet aggregation test group with an inhibition of $58.82 \pm 4.51 \%$ at $176 \mu \mathrm{M}$. Significant inhibition was not detected in the ADP-included platelet aggregation test group when adding $6 \mu \mathrm{M}$ CAPE.
When $46 \mu \mathrm{M}$ or more galangin was added to PRP, significant inhibition was detected in the collagen-included platelet aggregation test group in a dose-dependent manner. Galangin was not able to inhibit ADP-induced platelet aggregation until $370 \mu \mathrm{M}$ galangin had been added. Acacetin could significantly inhibit platelet aggregation induced by 
ADP, collagen, and TRAP at concentrations of 44,176 , and $352 \mu \mathrm{M}$ in the concentration-dependent manner $(P<0.05)$. The antiplatelet aggregation activity of pinostrobin isolated from propolis $(23 \mu \mathrm{M}, 92 \mu \mathrm{M}$, and $370 \mu \mathrm{M})$ was evaluated upon ADP-, collagen-, and TRAP-induced aggregation. As shown in Figures 1(f) and 2(f), the platelet aggregation could be suppressed by pinostrobin at concentrations of 23-370 $\mu \mathrm{M}(P<0.005)$. CAPE appeared to be more effective inhibitors than galangin and acacetin. This difference in potency could be explained by their chemical structures [34].

The isolated flavonoids markedly inhibited platelet aggregation induced by ADP, TRAP, and collagen. The inhibition might be introduced by holding back fibrinogen binding to its platelet membrane receptor (glycoprotein (GP) IIb-IIIa), which is a final and common pathway of platelet aggregation. It was reported that the flavonoid phloretin diminished ADP and TRAP-stimulated expression of the activated form of the GPIIb/IIIa complex and reduced platelet aggregation stimulated by ADP [30]. Several other studies had shown that flavonoids inhibited platelet function through a multitude of mechanisms including decreasing phospholipase $\mathrm{C}$ activity [31], scavenging of reactive oxygen species such as superoxide anion, and inhibiting cyclic nucleotide phosphodiesterase and thromboxane A2 synthesis [32].

\section{Conclusion}

The main components of propolis were galangin, CAPE, apigenin, quercetin, kaempferol, ferulic acid, rutin, chrysin, pinostrobin, and pinocembrin. The WEP and flavonoids extracted from propolis exhibited dose-dependent inhibitory effects on platelet aggregation induced by different agonists including ADP, collagen, and TRAP, respectively. CAPE, galangin, and pinostrobin might be mainly implicated. Further studies are necessary to clarify the mechanism of platelet inhibition.

\section{Conflicts of Interest}

The authors indicated no potential competing interests.

\section{Acknowledgments}

The authors are grateful for the generous financial support from the National Natural Science Foundation of China (no. 81573717), the National Key Technology R\&D Program of the Ministry of Science and Technology (no. 2013GA740103), the Scientific and Technological Development Project of Shandong Province (2015GSF118168) and the Department of Science and Technology of Weifang City (20100220).

\section{References}

[1] D. Massai, G. Cerino, D. Gallo et al., "Bioreactors as engineering support to treat cardiac muscle and vascular disease," Journal of Healthcare Engineering, vol. 4, no. 3, p. 329, 2013.

[2] X. Zhuang, "Challenges and methodologies of fully automatic whole heart segmentation: a review," Journal of Healthcare Engineering, vol. 4, no. 3, p. 371, 2013.
[3] E. Zahedi, V. Sohani, M. A. Ali, K. Chellappan, and G. K. Beng, "Experimental feasibility study of estimation of the normalized central blood pressure waveform from radial photoplethysmogram," Journal of Healthcare Engineering, vol. 6, no. 1, pp. 121-144, 2015.

[4] A. Papapanagiotou, G. Daskalakis, G. Siasos, A. Gargalionis, and A. G. Papavassiliou, "The role of platelets in cardiovascular disease: molecular mechanisms," Current Pharmaceutical Design, vol. 22, pp. 4493-4505, 2016.

[5] M. Ueno, M. Kodali, A. Tello-Montoliu, and D. J. Angiolillo, "Role of platelets and antiplatelet therapy in cardiovascular disease," Journal of Atherosclerosis and Thrombosis, vol. 18, pp. 431-442, 2011.

[6] R. Hernandez Hernandez, A. R. Carvajal, J. Guerrero Pajuelo et al., "The effect of doxazosin on platelet aggregation in normotensive subjects and patients with hypertension: an in vitro study," American Heart Journal, vol. 121, pp. 389394, 1991.

[7] V. Fuster, L. Badimon, J. J. Badimon, and J. H. Chesebro, "The pathogenesis of coronary artery disease and the acute coronary syndromes (1)," The New England Journal of Medicine, vol. 326, pp. 242-250, 1992.

[8] N. E. Barrett, L. Holbrook, S. Jones et al., "Future innovations in anti-platelet therapies," British Journal of Pharmacology, vol. 154, pp. 918-939, 2008.

[9] E. Szliszka, A. Sokół-Łętowska, A. Z. Kucharska, D. Jaworska, Z. P. Czuba, and W. Król, "Ethanolic extract of Polish propolis: chemical composition and TRAIL-R2 death receptor targeting apoptotic activity against prostate cancer cells," EvidenceBased Complementary and Alternative Medicine, vol. 2013, Article ID 757628, 12 pages, 2013.

[10] C. C. Gonçalves, L. Hernandes, C. A. Bersani-Amado, S. L. Franco, J. F. Silva, and M. R. Natali, "Use of propolis hydroalcoholic extract to treat colitis experimentally induced in rats by 2, 4, 6-trinitrobenzenesulfonic acid," Evidence-Based Complementary and Alternative Medicine, vol. 2013, Article ID 853976, 11 pages, 2013.

[11] R. S. Veiga, S. Mendonça, P. B. Mendes et al., "Artepillin C and phenolic compounds responsible for antimicrobial and antioxidant activity of green propolis and Baccharis dracunculifolia DC," Journal of Applied Microbiology, vol. 122, no. 4, pp. 911-920, 2017.

[12] K. M. Kasiotis, P. Anastasiadou, A. Papadopoulos, and K. Machera, "Revisiting Greek propolis: chromatographic analysis and antioxidant activity study," PLoS One, vol. 12, no. 1, article e0170077, 2017.

[13] M. C. Búfalo, A. P. Bordon-Graciani, B. J. Conti, G. M. de Assis, and J. M. Sforcin, "The immunomodulatory effect of propolis on receptors expression, cytokine production and fungicidal activity of human monocytes," Journal of Pharmacy and Pharmacology, vol. 66, no. 10, pp. 1497-1504, 2014.

[14] R. V. Ambardekar, K. R. Mahadik, A. R. Paradkar, and A. M. Harsulkar, "Enhancement of hepatoprotective efficacy of propolis by fabrication of liposomes, as a platform nanoformulation for multi-component natural medicine," Current Drug Delivery, vol. 9, no. 5, pp. 477-486, 2012.

[15] J. Wu, C. Omene, J. Karkoszka et al., "Caffeic acid phenethyl ester (CAPE), derived from a honeybee product propolis, exhibits a diversity of anti-tumor effects in pre-clinical models of human breast cancer," Cancer Letters, vol. 308, no. 1, pp. 43-53, 2011. 
[16] M. F. Tolba, S. S. Azab, A. E. Khalifa, S. Z. Abdel-Rahman, and A. B. Abdel-Naim, "Caffeic acid phenethyl ester, a promising component of propolis with a plethora of biological activities: a review on its anti-inflammatory, neuroprotective, hepatoprotective, and cardioprotective effects," IUBMB Life, vol. 65, no. 8, p. 699, 2013.

[17] S. De Marco, M. Piccioni, R. Pagiotti, and D. Pietrella, "Antibiofilm and antioxidant activity of propolis and bud poplar resins versus pseudomonas aeruginosa," EvidenceBased Complementary and Alternative Medicine, vol. 2017, Article ID 5163575, 11 pages, 2017.

[18] T. Bonamigo, J. F. Campos, T. M. Alfredo et al., "Antioxidant, cytotoxic, and toxic activities of propolis from two native bees in Brazil: Scaptotrigona depilis and Melipona quadrifasciata anthidioides," Oxidative Medicine and Cellular Longevity, vol. 2017, Article ID 1038153, 12 pages, 2017.

[19] A. P. Dos Santos Thomazelli, F. Tomiotto-Pellissier, S. S. da Silva et al., "Brazilian propolis promotes immunomodulation on human cells from American Tegumentar Leishmaniasis patients and healthy donors infected with L. braziliensis," Cellular Immunology, vol. 311, pp. 22-27, 2017.

[20] I. R. Babatunde, A. Abdulbasit, M. I. Oladayo, O. I. Olasile, F. R. Olamide, and B. W. Gbolahan, "Hepatoprotective and pancreatoprotective properties of the ethanolic extract of Nigerian propolis," Journal of Intercultural Ethnopharmacology, vol. 4, no. 2, pp. 102-108, 2015.

[21] K. Ren, W. Zhang, G. Wu et al., "Synergistic anti-cancer effects of galangin and berberine through apoptosis induction and proliferation inhibition in oesophageal carcinoma cells," Biomedicine \& Pharmacotherapy, vol. 84, pp. 17481759, 2016.

[22] G. Liu, W. Xie, A. D. He et al., "Antiplatelet activity of chrysin via inhibiting platelet $\alpha \mathrm{IIb} \beta 3$-mediated signaling pathway," Molecular Nutrition \& Food Research, vol. 60, no. 9, pp. 1984-1993, 2016.

[23] E. Lih, J. W. Jung, Y. K. Joung, D. J. Ahn, and D. K. Han, "Synergistic effect of anti-platelet and anti-inflammation of drug-coated Co-Cr substrates for prevention of initial instent restenosis," Colloids and Surfaces B: Biointerfaces, vol. 140, pp. 353-360, 2016.

[24] A. Russo, R. Longo, and A. Vanella, "Antioxidant activity of propolis: role of caffeic acid phenethyl ester and galangin," Fitoterapia, vol. 73, Supplement 1, pp. S21-S29, 2002.

[25] X. Guo, B. Chen, L. Luo, X. Zhang, X. Dai, and S. Gong, "Chemical compositions and antioxidant activities of water extracts of Chinese propolis," Journal of Agricultural and Food Chemistry, vol. 59, no. 23, pp. 12610-12616, 2011.

[26] Y. X. Zhang, Z. X. Yang, W. An, and J. F. Wang, "Effects of different solvents on the extraction rate of propolis flavonoids (in Chinese)," Lishizhen Medicine and Material Medical Research, vol. 17, no. 1, pp. 9-10, 2006.

[27] J. R. Sheu, C. R. Lee, C. C. Lin et al., "The antiplatelet activity of PMC, a potent $\alpha$-tocopherol analogue, is mediated through inhibition of cyclo-oxygenase," British Journal of Pharmacology, vol. 127, no. 5, pp. 1206-1212, 1999.

[28] M. Roest, J. J. Sixma, Y. P. Wu et al., "Platelet adhesion to collagen in healthy volunteers is influenced by variation of both alpha (2) beta (1) density and von Willebrand factor," Blood, vol. 96, no. 4, pp. 1433-1437, 2000.

[29] Y. P. Wu, A. Huisman, C. Weeterings et al., "Caffeic acid phenyl ester, a component of the Chinese herb propolis, inhibits platelet aggregation via competition with fibrinogen for binding to aIIbb3," Blood, vol. 112, pp. 53-67, 2008.

[30] Z. Cui-ping, H. Shuai, W. Wen-ting et al., "Development of high-performance liquid chromatographic for quality and authenticity control of Chinese propolis," Journal of Food Science, vol. 79, pp. C1315-C1322, 2014.

[31] C. B. S. M. Beatriz, C. C. P. José, and D. H. Miriam, "Concentration of flavonoids and phenolic compounds in aqueous and ethanolic propolis extracts through nanofiltration," Journal of Food Engineering, vol. 96, no. 4, pp. 533-539, 2010.

[32] S. H. Tzeng, W. Ko, C. Ko FN, and C. M. Teng, "Inhibition of platelet aggregation by some flavonoids," Thrombosis Research, vol. 64, no. 1, pp. 91-100, 1991.

[33] J. G. Keevil, H. E. Osman, J. D. Reed, and J. D. Folts, “Grape juice, but not orange juice or grapefruit juice, inhibits human platelet aggregation," Journal of Nutrition, vol. 130, no. 1, pp. 53-56, 2000.

[34] E. Middleton Jr and G. Drzewiecki, "Flavonoid inhibition of human basophil histamine release stimulated by various agents," Biochemical Pharmacology, vol. 33, no. 21, p. $3333,1984$. 


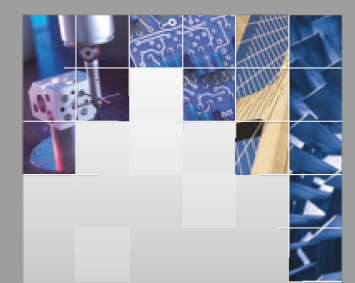

\section{Enfincering}
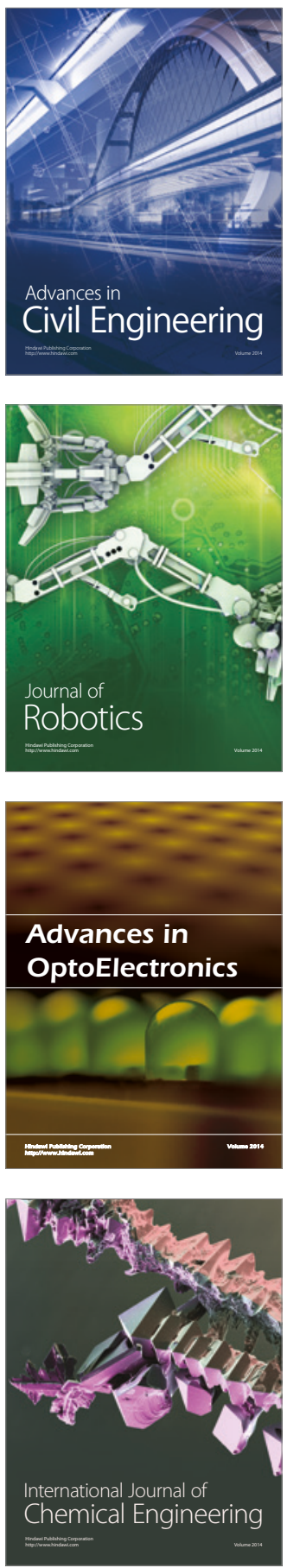

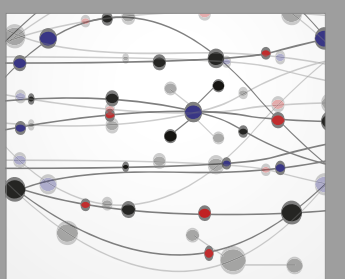

The Scientific World Journal

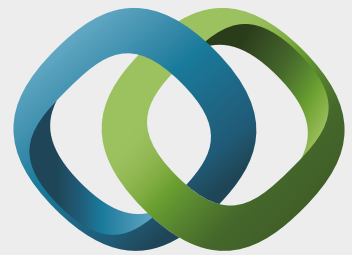

\section{Hindawi}

Submit your manuscripts at

https://www.hindawi.com
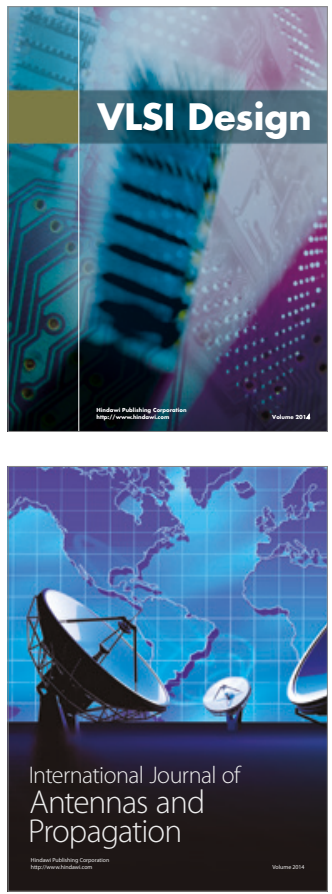

\section{Rotating}

Machinery
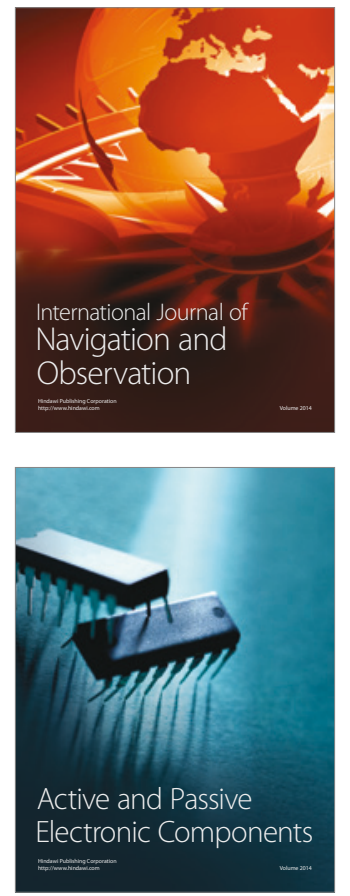
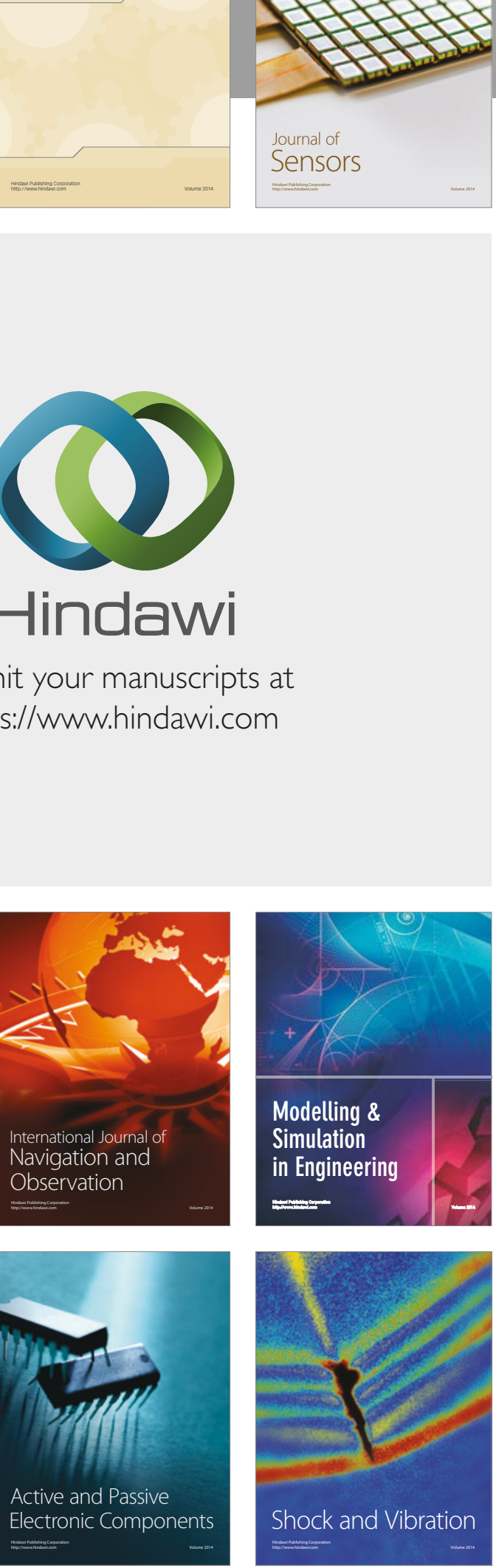
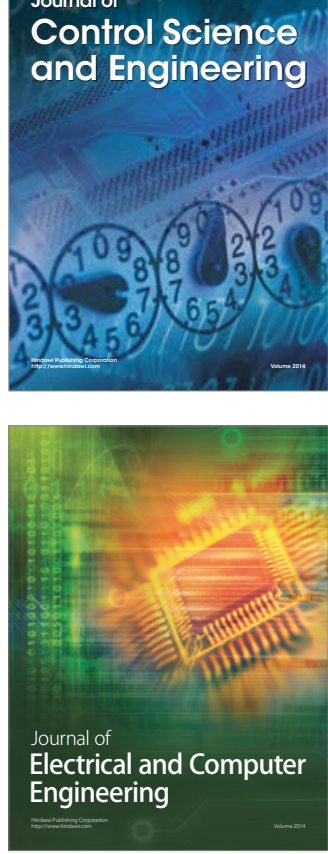

Distributed

Journal of

Control Science

and Engineering
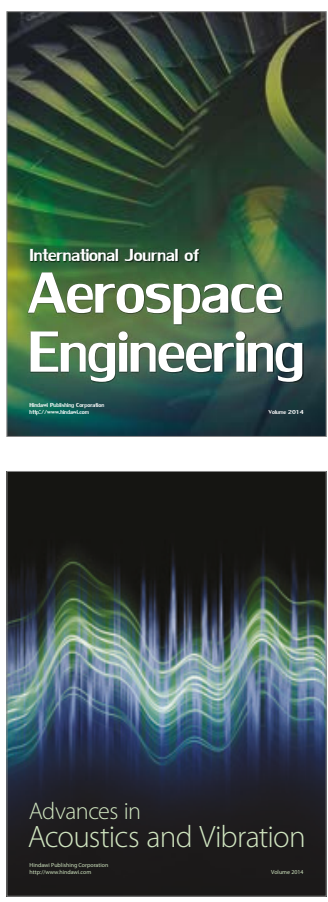

Sensor Networks 